\title{
16
}

\section{Reliability of Design Storms used to Size Urban Stormwater System Elements}

\section{Umar Malik and William James}

The objective of this study was to generate hydrographs using design storms and real rain data recorded over a $30 \mathrm{y}$ time period. In the first step rainfall characteristics were investigated using Intensity-Duration-Frequency (IDF) relationships. IDF curves were developed, called UM IDF curves, and when compared to the official Hamilton IDF curves showed a striking similarity for events with low return periods, and some variation for 50 and $100 \mathrm{y}$ return periods. From the UM IDF curves three new design storms (SCS type 2, AES Canadian and Chicago Storm), referred to as UM Design Storms, were developed for comparison with the Hamilton design storms. The differences in intensity-duration of the less frequent storms (observed in the IDF comparison) were also reflected in the design storm volume and peak discharge. All the different design distributions, for a wide range of return periods, were entered into the rainfall-runoff model, PCSWMM, for event simulation of design storms. PCSWMM was also run for continuous simulation of the coarse observed data. Keeping the geomorphic conditions and loss parameters constant, differences were quantified in terms of computed flow and storage capacities for two design applications. The designs derived from the coarse observed data were considered to be optimal and used to decide suitability or otherwise of the designs based on other synthetic distribution patterns, and it was found that almost all the

Malik, U. and W. James. 2007. "Reliability of Design Storms used to Size Urban Stormwater System Elements." Journal of Water Management Modeling R227-16. doi: 10.14796/JWMM.R227-16.

(C) CHI 2007 www.chijournal.org ISSN: 2292-6062 (Formerly in Contemporary Modeling of Urban Water Systems. ISBN: 0-9736716-3-7) 
application designs obtained from design storm hyetographs were overdesigned. In other words, for every return period, the flow capacity and detention storage required to accommodate the design storm hydrographs was greater than what would be required if the same applications were designed for historic storms in continuous simulation. Given the coarse continuous data these results are to be expected, and should be reexamined when continuous at a fine time step become available.

Evidently design storms generate a hydrograph with greater volume and a higher peak, requiring more detention storage, greater flow capacity and larger pipe sizes, than using coarse continuous simulation. It is still not yet clear whether structures based on design storms are over-sized and costlier than necessary.

The study showed that SCS type 2 and the AES Canadian design storms yield flow and storage capacities relatively closer to the coarse continuous data while the Chicago design storms produce over-sized flow and storage capacities. The latter may be deemed to not provide representative rainfall distributions for Southern Ontario.

\subsection{Introduction}

Design storms are widely accepted by hydrological engineers as input for drainage and runoff studies. The average intensity of design storms is usually computed using the total rainfall volume obtained from local IDF curves for specified storm durations. Temporal distributions of design storms are provided by established mass curves. Several methods, using different mass-curve templates, are available for developing design storms; however the temporal distribution of these storms may be quite unlike many of the rainstorms observed at a specific catchment. This chapter compares and evaluates results obtained from different methods of synthesizing a design storm and compares the resulting designs of stormwater system elements with elements designed using a coarse continuous time series. Finally a methodology for evaluating the reliability of the designs generated by the various design storms is suggested.

Continuous simulation in hydrologic design has also attracted some interest. The biggest barrier to the continuous, period-of-record approach is the absence of long rainfall records of appropriate temporal resolution. CDRoms from Earth Info contain hourly data dating back to 1950s but no such long-term record exists for shorter time steps. Thus for this study the 
writers used a $30 \mathrm{y}$ rainfall record of $1 \mathrm{~h}$ resolution to produce IDF curves, and from the derived IDF curves, three different types of storms: SCS Type $2(24 \mathrm{~h})$ distribution (for Ontario), AES Canadian (1 h) Design Storm (for Southern Ontario conditions) and the IDF curve-based Chicago $(3 \mathrm{~h})$ Synthetic Storm were derived for a range of return periods: 2, 5, 10, 25, 50 and $100 \mathrm{y}$. The scope of the exercise was to (i.) use the design storm procedures and the coarse rainfall record to design a stormwater collection system and finally (ii.) compare the resulting designs for:

1. flow capacity, and

2. storage capacity,

For an engineered drainage structure to perform appropriately and to prevent failure, determining a correct or a reasonable design flow is critically important. Design flow is based on a recurrence frequency that depends on the type and value of the structure. The three design storms above were used to design flow capacity and the results compared to the design capacity determined using the coarse rain record.

BMPs for flood control aim to control peak discharge, by providing sufficient storage. Storage facilities are typically ponds. The RAINFALL, RUNOFF, and TRANSPORT Modules of PCSWMM were used to compute flow and storage capacities for the design and continuous hyetographs.

Failure of design in the scope of this study has the following meaning. A properly designed project should pass the design runoff at full capacity. If the design runoff is exceeded, the structure is said to fail. Failure does not necessarily mean physical collapse of the structure; not functioning as intended is considered failure. A factor of safety is introduced to rate the design. The two applications were sized using the three design storms for the six return periods and also using the coarse, long-term rainfall, and the 42 results compared by to the devised factor of safety. Conclusions were drawn regarding the quality of design produced by the three design storm methods.

\subsection{Intensity - Duration - Frequency Curves}

For IDF analysis, annual maximum rainfall intensities of 5, 10, 15, $30 \mathrm{~min}$, $1,2,3,6$ and $12 \mathrm{~h}$ durations were extracted from the 30 -y rain record for the city of Hamilton. The Weibull plotting position was used in the frequency analysis and to estimate the probability of exceedance for maximum rainfall depth of each year and for each duration. A log-normal distribution was then fitted to the curves. 


$$
Y=a \ln (x)+b
$$

where:

$$
\begin{aligned}
Y & =\text { the maximum rainfall depth, } \\
x & =\text { the return period, and } \\
a, b & =\text { the distribution parameters. }
\end{aligned}
$$

An average coefficient of determination of 0.923 was obtained, which indicates a good log normal distribution fit. Using the parameter values from each curve, the average intensity depths for the given return periods were computed. Table 16.1 shows the computed average rain intensities for various durations and return periods.

Table 16.1 Average rain intensities for various durations and return periods.

\begin{tabular}{ccccccc}
\hline $\begin{array}{c}\text { Duration } \\
(\mathrm{min})\end{array}$ & $2 \mathrm{y}$ & $5 \mathrm{y}$ & $10 \mathrm{y}$ & $25 \mathrm{y}$ & $50 \mathrm{y}$ & $100 \mathrm{y}$ \\
\hline 5 & 97.7 & 141.8 & 175.1 & 219.2 & 252.6 & 286.0 \\
10 & 68.2 & 101.8 & 127.1 & 160.6 & 185.9 & 211.3 \\
15 & 55.3 & 82.5 & 103.1 & 130.4 & 151.0 & 171.7 \\
30 & 37.5 & 56.0 & 70.0 & 88.5 & 102.5 & 116.5 \\
60 & 23.2 & 36.5 & 46.6 & 59.9 & 70.0 & 80.1 \\
120 & 14.2 & 22.0 & 27.9 & 35.7 & 41.7 & 47.6 \\
360 & 6.2 & 9.6 & 12.1 & 15.5 & 18.1 & 20.6 \\
720 & 3.5 & 5.3 & 6.7 & 8.5 & 9.8 & 11.2 \\
1440 & 2.1 & 3.0 & 3.7 & 4.7 & 5.4 & 6.1 \\
\hline
\end{tabular}

The City of Hamilton IDF curves are based on IDF curve fitting parameters A, B and C, obtained from the city of Hamilton. The Hamilton and the UM IDF curves based on the Weibull plotting position and the Lognormal distribution formula were compared graphically. Plots for the 2, 5, 10 , and 25 y return periods show a close similarity while some variation is seen in the $50 \mathrm{y}$ and $100 \mathrm{y}$ events. Small differences were also observed in the 5-minute duration events for all return periods, the Hamilton curves being lower than the UM IDF curves. These observations indicate problems in accuracy associated with longer return periods. There are various estimations for those events and no rainfall data exists to confirm and 
establish the intensities. Note that the City of Hamilton relationships were developed using the Gumbel method of moments, while the UM rainfall intensities were obtained using the Weibull plotting position and Log normal distribution. A typical comparison of the UM and the Hamilton IDF curves is shown in Figure 16.1.

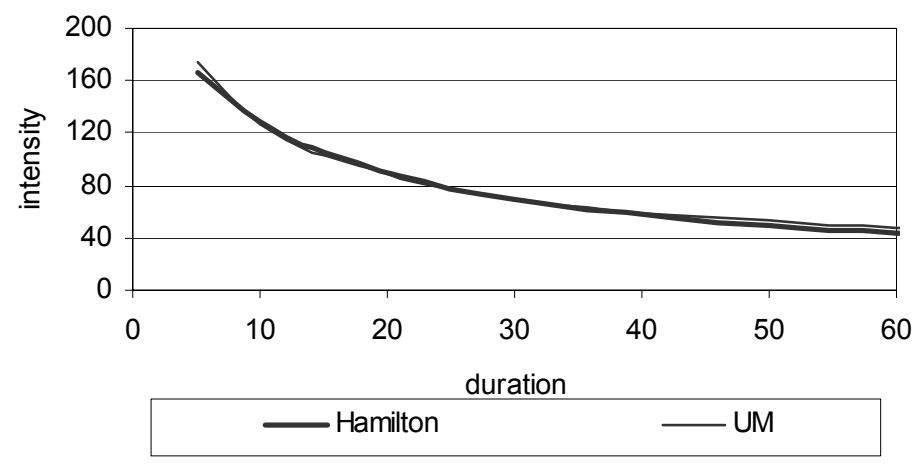

Figure 16.1 Comparing UM and Hamilton IDF curves.

\subsection{Design Storms}

The purpose of design storms is to provide a design basis for various hydraulic structures, for instance pipes and detention basins (Hall, 1984). Design storms are coupled with a return interval and it is assumed that the flow hydrograph generated by the design storm has the same return frequency as the storm hyetograph. Being easy to use, design storms have found extensive use in the design of hydraulic structures. The method of constructing a design storm does not require an extensive rainfall record. It is instead linked to IDF curves. For any specified duration, the corresponding rainfall intensity is obtained from the IDF curves of the desired return period. The rainfall depth is then distributed over the duration of the storm in a pattern specified by the synthetic storm design procedure. Care needs to be taken that the "best" design storm is chosen and used properly within the range of its applicability (Marsalek and Watt 1984).

In this study the SCS type 2 distribution was selected for its relevance to Ontario precipitation patterns, and for AES Canadian design storms the 
distribution typical for southern Ontario was selected. The AES synthetic distribution is based on regional average values of time-to-peak-intensity, peak/total depth, and rainfall amount prior to peak (Hogg 1982). The Chicago $3 \mathrm{~h}$ storm is based on the assumption that for a particular return period, the design storm should contain all maxima corresponding to various durations (Watt et al, 1989). The Chicago distribution is obtained directly from the IDF curves and in spite of lack of evidence of its suitability to Canadian conditions, is frequently used in hydrological analysis. The distribution was included in this exercise to assess how it compares with the SCS type 2 and AES Canadian design storms. Two sets of design storms were developed for the whole range of return periods $(2,510,25,50$ and $100 \mathrm{y}$ ): (i.) the UM design storms, linked to UM IDF curves, and (ii.) the Hamilton design storms, linked to the city of Hamilton official IDF curves.

The Chicago Design Storm is based on the IDF relation:

$$
i=\frac{A}{\left(t_{d}+B\right)^{C}}
$$

where $\mathrm{A}, \mathrm{B}$ and $\mathrm{C}$ are curve fitting parameters.

The storm duration assumed for the Chicago Design Storm is 180 minutes and the time to peak is taken to be $r=0.4$. The intensities before the peak are given by:

$$
i=\frac{A\{(1-C)(t-t / r)+B\}}{\left\{\left(t_{d}-t / r\right)+B\right\}^{C}}
$$

and intensities after the peak are given by:

$$
i=\frac{A\left\{(1-C)\left(\frac{t-r^{*} t}{1-r}\right)+B\right\}}{\left\{\left(\frac{t-r^{*} t_{d}}{1-r}\right)+B\right\}^{1+C}}
$$

Figure 16.2 shows a typical comparison of UM and Hamilton SCS design storms. 


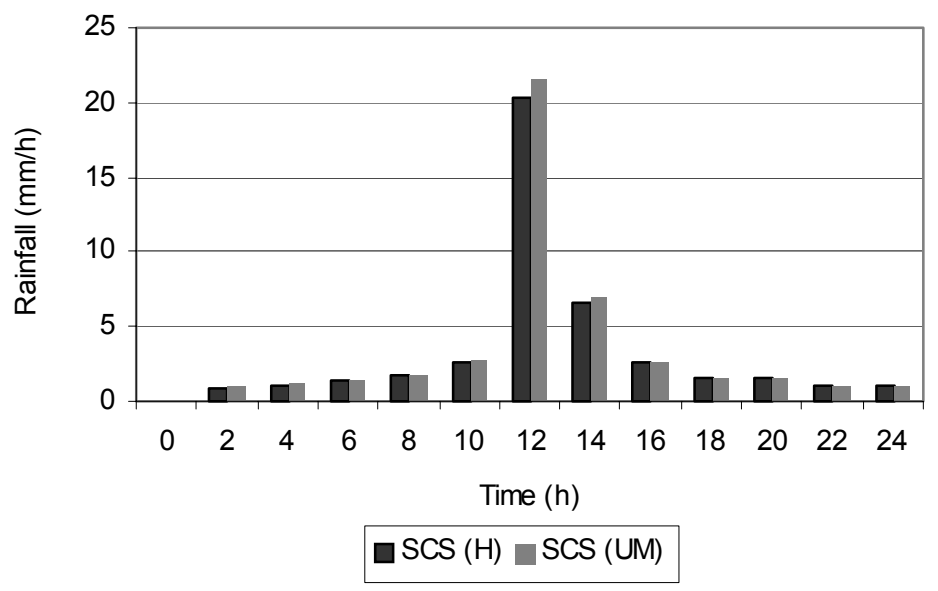

Figure 16.2 Comparing a typical 10 y return SCS design storm.

\subsection{Application of PCSWMM}

Hydrologic models provide a quantitative estimate of stormwater runoff and stormwater management facilities. PCSWMM was used to compute response to SCS type $2(24 \mathrm{~h})$, AES Canadian $(1 \mathrm{~h})$ and Chicago $(3 \mathrm{~h})$ synthetic design storms for the range of return periods. For each design storm and for each return interval, two sets of design storms were developed from the rainfall record. The UM storms represent the storms designed by the writers while the Hamilton storms are those that have been constructed based on the rainfall analysis obtained from the city of Hamilton. The RAIN, RUNOFF and TRANSPORT Modules of PCSWMM were used for hydrologic modeling.

The RAIN Module reads the rainfall inputs. The data was provided as design storm distribution patterns and the long time-series of precipitation records. The former was entered using Environment Canada's Atmospheric Environment Services precipitation format, and the latter in the usergenerated precipitation time series for a continuous simulation. The $30 \mathrm{y}$ observed rainfall record, in Figure 16.3, was simulated in the continuous model by creating a User-Defined rainfall input format. The overland flows 
generated by the RUNOFF module were subsequently entered into the TRANSPORT Module for flow routing. (James et al., 2003)

Table 16.2 The Stormwater System element characteristics.

\begin{tabular}{l|ccc}
\hline Element & \multicolumn{3}{|c}{ Conduit } \\
\hline Type & \multicolumn{3}{c}{ Circular pipe } \\
\hline \multirow{2}{*}{ Length } & $200 \mathrm{~m}$ & $200 \mathrm{~m}$ & $200 \mathrm{~m}$ \\
\cline { 2 - 4 } Diameter & \multicolumn{2}{|c}{ Varies with design storms and return periods } \\
\cline { 2 - 4 } Conduit slope & $5 \%$ & $5 \%$ & $5 \%$ \\
$\begin{array}{l}\text { Manning's } \\
\text { rawohnecc }\end{array}$ & 0.014 & 0.014 & 0.014 \\
\hline
\end{tabular}

Table 16.3 Subcatchment characteristics.

\begin{tabular}{l|ccc}
\hline Element & \multicolumn{3}{|c}{ Subcatchment } \\
\hline Width & $400 \mathrm{~m}$ & $600 \mathrm{~m}$ & $800 \mathrm{~m}$ \\
Area & $40 \mathrm{ha}$ & $40 \mathrm{ha}$ & $40 \mathrm{ha}$ \\
Imperviousness & $20 \%$ & $20 \%$ & $20 \%$ \\
Ground slope & $4 \%$ & $4 \%$ & $4 \%$ \\
Manning's roughness (Imp) & 0.02 & 0.02 & 0.02 \\
Manning's roughness (Perv) & 0.3 & 0.3 & 0.3 \\
Depression storage (Imp) & $0.25 \mathrm{~mm}$ & $0.25 \mathrm{~mm}$ & $0.25 \mathrm{~mm}$ \\
Depression storage (Perv) & $0.5 \mathrm{~mm}$ & $0.5 \mathrm{~mm}$ & $0.5 \mathrm{~mm}$ \\
\cline { 2 - 4 } Infiltration equation & \multicolumn{3}{|c}{ Green \& Ampt. } \\
\cline { 2 - 4 } Max initial infiltration & $25 \mathrm{~mm} / \mathrm{h}$ & $25 \mathrm{~mm} / \mathrm{h}$ & $25 \mathrm{~mm} / \mathrm{h}$ \\
Max infiltration rate & $6 \mathrm{~mm} / \mathrm{h}$ & $6 \mathrm{~mm} / \mathrm{h}$ & $6 \mathrm{~mm} / \mathrm{h}$ \\
\hline
\end{tabular}

Sizes, shapes, characteristics and properties of the elements and subcatchments are detailed in Tables 16.2 and 16.3. Since the objective of the exercise was a simple comparison of the hypothetical runoff generated by design storms and a long-term observed rainfall, the element characteristics were chosen arbitrarily.

Set NDESIGN $=1$ in TRANSPORT for auto-design of flow capacity. 


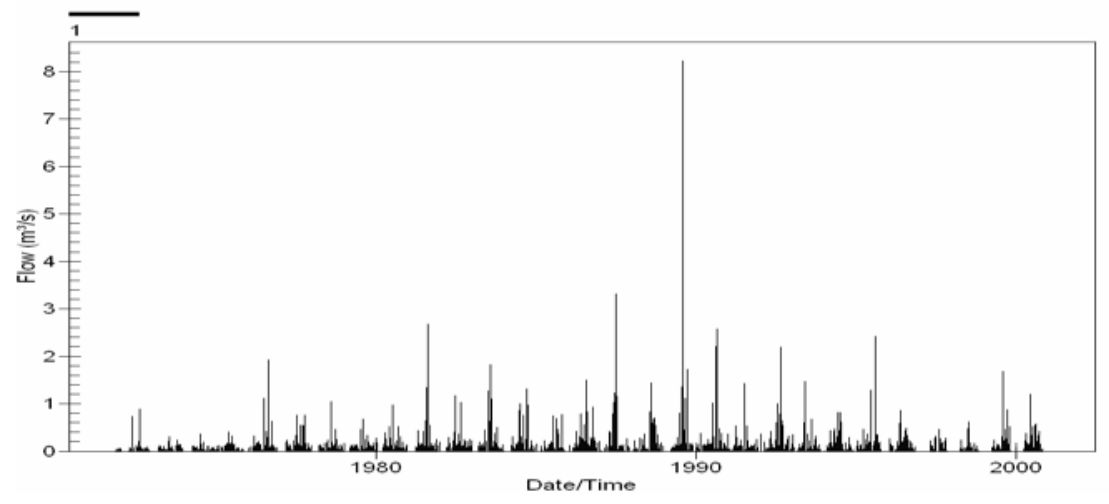

Figure 16.3 Hydrograph for rain record 1970 to 2001 (PCSWMM)

Table 16.4 shows a typical result of design of flow capacity for input hydrographs. Designs for other return periods have been omitted for brevity.

Table 16.4 Comparison of pipe sizes for different design storms (All sizes are commercially available)

\begin{tabular}{l|lcccccc}
\hline $\begin{array}{l}\text { Return } \\
\text { period }\end{array}$ & $\begin{array}{c}\text { Design } \\
\text { Storm }\end{array}$ & \multicolumn{3}{c}{ Conduit ID 10 } & \multicolumn{2}{c}{ Conduit ID 20 } & \multicolumn{2}{c}{ Conduit ID 30 } \\
\cline { 3 - 8 } & & $\begin{array}{c}\text { Size } \\
(\mathrm{m})\end{array}$ & $\begin{array}{c}\text { Flow } \\
\left(\mathrm{m}^{3} / \mathrm{s}\right)\end{array}$ & $\begin{array}{c}\text { Size } \\
(\mathrm{m})\end{array}$ & $\begin{array}{c}\text { Flow } \\
\left(\mathrm{m}^{3} / \mathrm{s}\right)\end{array}$ & $\begin{array}{c}\text { Size } \\
(\mathrm{m})\end{array}$ & $\begin{array}{c}\text { Flow } \\
\left(\mathrm{m}^{3} / \mathrm{s}\right)\end{array}$ \\
\hline \multirow{6}{*}{$10 \mathrm{y}$} & SCS $(\mathrm{H})$ & 0.762 & 2.082 & 0.762 & 2.377 & 1.219 & 7.092 \\
& SCS(UM) & 0.762 & 2.253 & 0.838 & 2.664 & 1.219 & 7.737 \\
& AES (H) & 0.838 & 2.987 & 0.914 & 3.463 & 1.372 & 10.073 \\
& AES(UM) & 0.838 & 3.235 & 0.914 & 3.659 & 1.372 & 10.846 \\
& Chic (H) & 1.067 & 4.698 & 1.067 & 5.34 & 1.524 & 15.682 \\
& Chi (UM) & 1.067 & 4.644 & 1.067 & 5.28 & 1.524 & 15.543 \\
\hline
\end{tabular}

The STATISTICS module of PCSWMM was used to perform a simple statistical analysis on the quantity parameters. The data for the statistical module is read from the interface file of the TRANSPORT module. The output file includes a table of sequential series of events with the date and time of occurrence of each event, total rainfall and flow for each event and 
the inter-event period. The output file also includes a rank order table of the magnitude, return period, frequency and date of the thirty most extreme events. The events representing the selected return periods were chosen for analysis. The hydrographs of these storm events were then routed using the TRANSPORT module to obtain the minimum pipe size required to contain the maximum generated flow. Results are given in Table 16.5.

Table 16.5 Conduit sizes for return events from observed rain data.

Conduit sizes $(\mathrm{m})$ and flow in $\mathrm{m}^{3} / \mathrm{s}$

\begin{tabular}{ccccccccc}
\hline $\begin{array}{l}\text { Return } \\
\text { Period }\end{array}$ & \multicolumn{2}{c}{ Date of Event } & \multicolumn{3}{c}{ Conduit ID 10 } & \multicolumn{2}{c}{ Conduit ID 20 } & \multicolumn{2}{c}{ Conduit ID 30 } \\
\cline { 2 - 9 } & Year & $\mathrm{d} / \mathrm{m}$ & Size & Flow & Size & Flow & Size & Flow \\
\cline { 2 - 9 } $30 \mathrm{y}$ & 1989 & $25 / 7$ & 0.914 & 3.482 & 0.914 & 3.924 & 1.372 & 11.57 \\
$10 \mathrm{y}$ & 1990 & $27 / 8$ & 0.686 & 1.5 & 0.686 & 1.705 & 1.067 & 5.1 \\
$5 \mathrm{y}$ & 1995 & $10 / 8$ & 0.533 & 0.836 & 0.533 & 0.955 & 0.838 & 2.85 \\
$2 \mathrm{y}$ & 1993 & $25 / 5$ & 0.381 & 0.331 & 0.381 & 0.363 & 0.61 & 1.08 \\
\hline
\end{tabular}

\subsubsection{Comparing Design Pipe Sizes}

Table 16.6 provides a comparison of the pipe sizes obtained from the above procedure. Figure 16.4 compares the sizes graphically.

Table 16.6 Comparison of pipe sizes required top contain flows from design events and observed rain. (The $25 \mathrm{y}$ design event has been compared with the $30 \mathrm{y}$ event of the observed rain analyses).

\begin{tabular}{cccccccc}
\hline $\begin{array}{c}\text { Ret } \\
\text { Period }\end{array}$ & $\begin{array}{c}\text { SCS } \\
(\mathrm{H})\end{array}$ & $\begin{array}{c}\text { SCS } \\
(\mathrm{UM})\end{array}$ & $\begin{array}{c}\text { AES } \\
(\mathrm{H})\end{array}$ & $\begin{array}{c}\text { AES } \\
(\mathrm{UM})\end{array}$ & $\begin{array}{c}\text { Chic } \\
(\mathrm{H})\end{array}$ & $\begin{array}{c}\text { Chic } \\
(\mathrm{UM})\end{array}$ & $\begin{array}{c}\text { Observed } \\
\text { Rain }\end{array}$ \\
\hline $2 \mathrm{y}$ & 0.914 & 0.914 & 1.067 & 1.067 & 1.219 & 1.219 & 0.61 \\
$5 \mathrm{y}$ & 1.067 & 1.067 & 1.219 & 1.219 & 1.372 & 1.524 & 0.838 \\
$10 \mathrm{y}$ & 1.219 & 1.219 & 1.372 & 1.372 & 1.524 & 1.524 & 1.067 \\
$25 \mathrm{y}$ & 1.219 & 1.372 & 1.524 & 1.524 & 1.676 & 1.676 & 1.372 \\
\hline
\end{tabular}




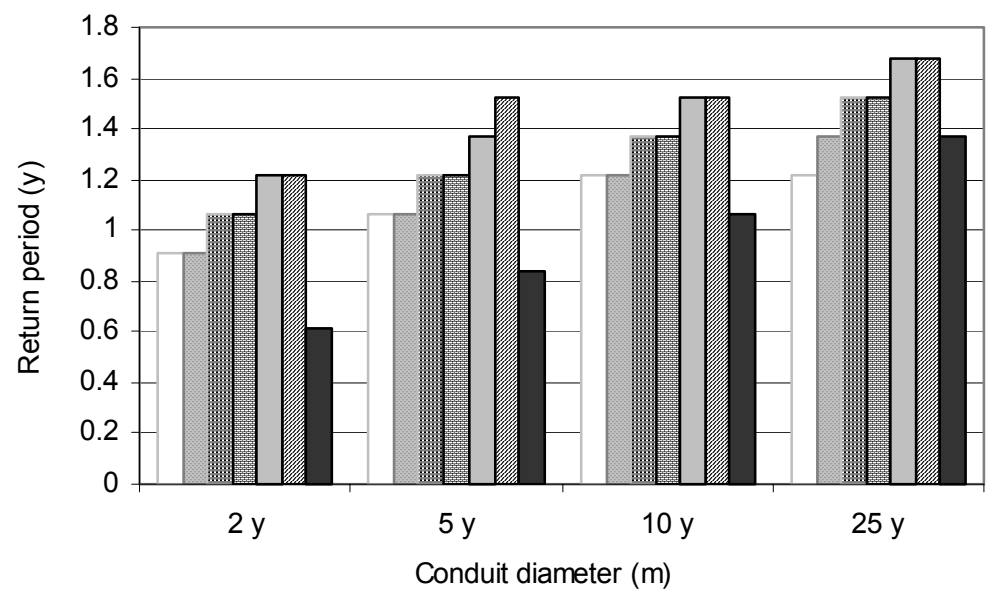

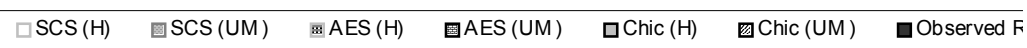

Figure 16.4 Graphical comparison of conduit sizes.

16.4.2 Comparing Design Flows through Conduit 30

Table 16.7 and Figure 16.5 compare the maximum flows generated by different storms and by the long-term rain record.

Table 16.7 Comparison of flows through conduit 30.

\begin{tabular}{cccccccc}
\hline $\begin{array}{c}\text { Ret } \\
\text { Period }\end{array}$ & $\begin{array}{c}\text { SCS } \\
(\mathrm{H})\end{array}$ & $\begin{array}{c}\text { SCS } \\
(\mathrm{UM})\end{array}$ & $\begin{array}{c}\text { AES } \\
(\mathrm{H})\end{array}$ & $\begin{array}{c}\text { AES } \\
(\mathrm{UM})\end{array}$ & $\begin{array}{c}\text { Chic } \\
(\mathrm{H})\end{array}$ & $\begin{array}{c}\text { Chic } \\
(\mathrm{UM})\end{array}$ & $\begin{array}{c}\text { Observed } \\
\text { Rain }\end{array}$ \\
\hline $2 \mathrm{y}$ & 3.805 & 3.558 & 4.874 & 4.487 & 8.614 & 8.344 & 1.084 \\
$5 \mathrm{y}$ & 5.681 & 5.766 & 7.935 & 8.026 & 11.837 & 12.198 & 2.85 \\
$10 \mathrm{y}$ & 7.092 & 7.737 & 10.073 & 10.846 & 15.682 & 15.543 & 5.1 \\
$25 \mathrm{y}$ & 8.96 & 10.487 & 13.05 & 14.869 & 18.833 & 20.421 & 11.57 \\
\hline
\end{tabular}




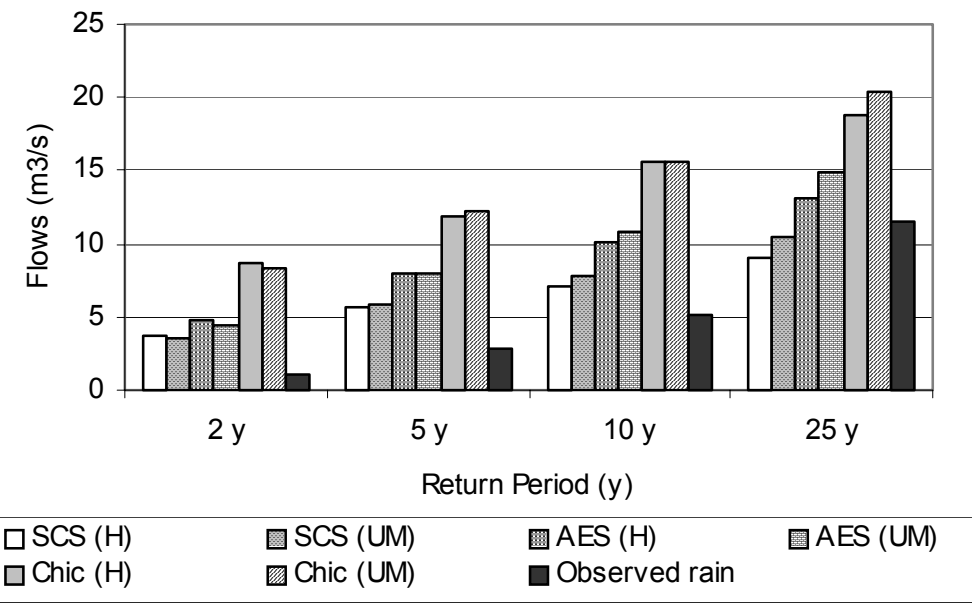

Figure 16.5 Flow comparison of design events and observed rain.

To examine the response from bigger catchments, the area of each of the three subcatchments was increased to $1 \mathrm{~km}^{2}$ (100 ha) with a width of $500 \mathrm{~m}$ and a slope of $1 \%$ each. Conduit lengths were assumed to be $1000 \mathrm{~m}$ each and were all assumed to be at 1\% slope. As shown in Figures 16.6 and 16.7 and Tables 16.8 and 16.9, it was found that the response of the larger subcatchments was the same as for the smaller catchments. Evidently for subcatchments up to $1 \mathrm{~km}^{2}$, the significant differences in designs should not be attributed primarily to catchment area.

Table 16.8 Design conduit diameters (m) for 100 ha subcatchment.

\begin{tabular}{cccccccc}
\hline $\begin{array}{c}\text { Ret } \\
\text { Period }\end{array}$ & $\begin{array}{c}\text { SCS } \\
(\mathrm{H})\end{array}$ & $\begin{array}{c}\text { SCS } \\
(\mathrm{UM})\end{array}$ & $\begin{array}{c}\text { AES } \\
(\mathrm{H})\end{array}$ & $\begin{array}{c}\text { AES } \\
(\mathrm{UM})\end{array}$ & $\begin{array}{c}\text { Chic } \\
(\mathrm{H})\end{array}$ & $\begin{array}{c}\text { Chic } \\
(\mathrm{UM})\end{array}$ & $\begin{array}{c}\text { Observed } \\
\text { Rain }\end{array}$ \\
\hline $2 \mathrm{y}$ & 1.524 & 1.37 & 1.524 & 1.372 & 1.676 & 1.676 & 1.067 \\
$5 \mathrm{y}$ & 1.676 & 1.676 & 1.83 & 1.83 & 2 & 2 & 1.37 \\
$10 \mathrm{y}$ & 1.83 & 1.83 & 2 & 2 & 2.13 & 2.13 & 1.524 \\
$25 \mathrm{y}$ & 2 & 2 & 2.134 & 2.28 & 2.28 & 2.44 & 2 \\
\hline
\end{tabular}




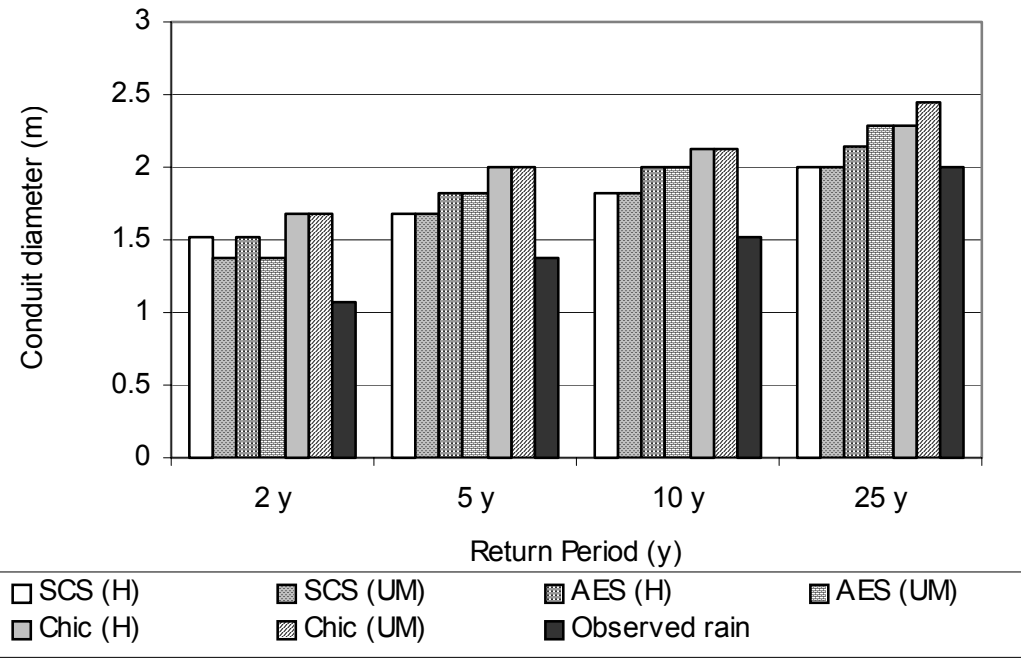

Figure 16.6 Comparing design conduit diameters for a 100 ha subcatchment.

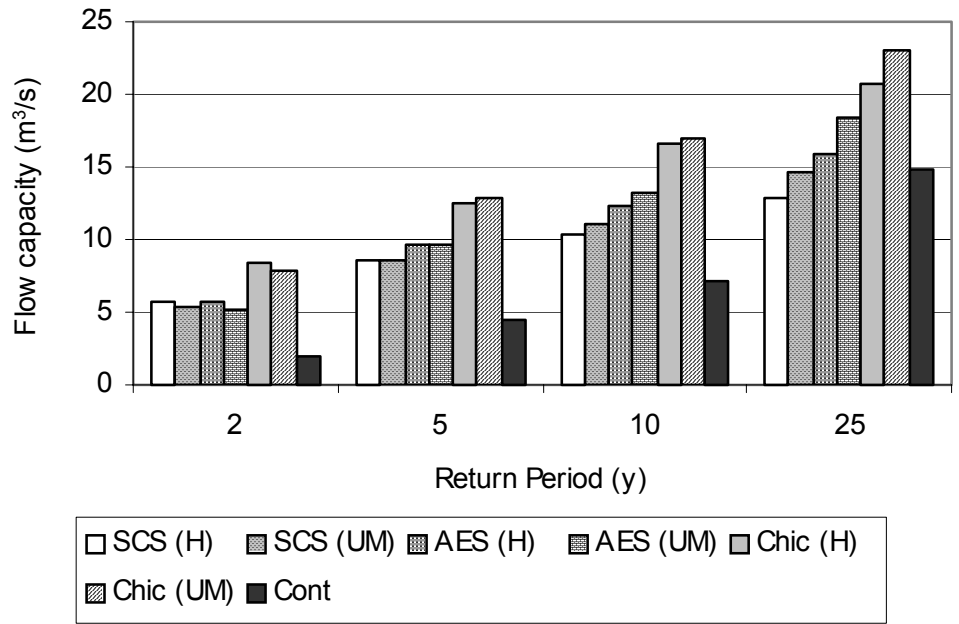

Figure 16.7 Comparing design flows for 100 ha subcatchment. 
Table 16.9 Design Flows $\left(\mathrm{m}^{3} / \mathrm{s}\right)$ from 100 ha subcatchment

\begin{tabular}{cccccccc}
\hline $\begin{array}{c}\text { Ret } \\
\text { Period }\end{array}$ & $\begin{array}{c}\text { SCS } \\
(\mathrm{H})\end{array}$ & $\begin{array}{c}\text { SCS } \\
(\mathrm{UM})\end{array}$ & $\begin{array}{c}\text { AES } \\
(\mathrm{H})\end{array}$ & $\begin{array}{c}\text { AES } \\
(\mathrm{UM})\end{array}$ & $\begin{array}{c}\text { Chic } \\
(\mathrm{H})\end{array}$ & $\begin{array}{c}\text { Chic } \\
(\mathrm{UM})\end{array}$ & $\begin{array}{c}\text { Observed } \\
\text { Rain }\end{array}$ \\
\hline $2 \mathrm{y}$ & 5.8 & 5.4 & 5.72 & 5.19 & 8.32 & 7.82 & 2 \\
$5 \mathrm{y}$ & 8.52 & 8.64 & 9.7 & 9.7 & 12.52 & 12.83 & 4.5 \\
$10 \mathrm{y}$ & 10.33 & 11.07 & 12.34 & 13.3 & 16.68 & 17 & 7.08 \\
$25 \mathrm{y}$ & 12.87 & 14.63 & 15.83 & 18.475 & 20.7 & 23.12 & 14.75 \\
\hline
\end{tabular}

\subsubsection{Design Detention Storage}

The Storage utility in the TRANSPORT module was used to compute detention storage required at the outfall to limit discharge to a maximum of $2 \mathrm{~m}^{3} / \mathrm{s}$ at all times.

Table 16.10 Storage volume required for different design events.

\begin{tabular}{l|lc|c|c}
\hline $\begin{array}{c}\text { Return } \\
\text { period }\end{array}$ & \multicolumn{1}{|c|}{ Design Storm } & $\begin{array}{c}\text { Max Flow } \\
\left(\mathrm{m}^{3} / \mathrm{s}\right)\end{array}$ & $\begin{array}{c}\text { Out-flow } \\
\text { at node } 4 \\
\left(\mathrm{~m}^{3} / \mathrm{s}\right)\end{array}$ & $\begin{array}{c}\text { Storage volume at node 4 } \\
\left(\mathrm{m}^{3}\right)\end{array}$ \\
\hline \multirow{6}{*}{$10 \mathrm{y}$} & SCS type 2 (H) & 6.57 & & 14157 \\
& SCS type 2 (UM) & 7.6 & & 16491 \\
& AES 1 hr (H) & 9.6 & 2 & 16885 \\
& AES 1 hr (UM) & 10.07 & & 19212 \\
& Chicago 3h (H) & 8.6 & & 25442 \\
& Chicago 3h (UM) & 9.3 & & 28000 \\
\hline
\end{tabular}

The highest 30 events were selected for flow capacity analysis and were also used to determine the storage capacity required to accommodate the runoff generated by long-term rainfall record. Using the same procedure as for the design storms, the discharge at the outfall was limited to $2 \mathrm{~m}^{3} / \mathrm{s}$ constantly. The required storage capacities are given in Tables 16.10 and 16.11 and Figure 16.8. Years with flows less than $2 \mathrm{~m}^{3} / \mathrm{sec}$ obviously showed no storage requirement. The uncharacteristically extreme event of 1989 yielding $11.59 \mathrm{~m}^{3} / \mathrm{s}$ runoff and requiring a storage capacity of 72,000 $\mathrm{m}^{3}$ and was treated as an outlier. 
Table 16.11 Comparison of event and long-term storage.

\begin{tabular}{cccccccc}
\hline $\begin{array}{c}\text { Ret } \\
\text { Period }\end{array}$ & $\begin{array}{c}\text { SCS } \\
(\mathrm{H})\end{array}$ & $\begin{array}{c}\text { SCS } \\
(\mathrm{UM})\end{array}$ & $\begin{array}{c}\text { AES } \\
(\mathrm{H})\end{array}$ & $\begin{array}{c}\text { AES } \\
(\mathrm{UM})\end{array}$ & $\begin{array}{c}\text { Chic } \\
(\mathrm{H})\end{array}$ & $\begin{array}{c}\text { Chic } \\
(\mathrm{UM})\end{array}$ & $\begin{array}{c}\text { Observed } \\
\text { Rain }\end{array}$ \\
\hline $2 \mathrm{y}$ & 3296 & 3007 & 4308 & 3576 & 6159 & 5397 & 1198 \\
$5 \mathrm{y}$ & 8154 & 8922 & 11113 & 11151 & 16500 & 17257 & 6353 \\
$10 \mathrm{y}$ & 14157 & 16491 & 16885 & 19212 & 25442 & 28000 & 10252 \\
$25 \mathrm{y}$ & 21418 & 27566 & 25275 & 31469 & 38275 & 45500 & 15407 \\
$50 \mathrm{y}$ & 28100 & 37612 & 32052 & 40476 & 45800 & 59300 & 19306 \\
$100 \mathrm{y}$ & 34500 & 47431 & 38168 & 49560 & 55275 & 73000 & 23205 \\
\hline
\end{tabular}

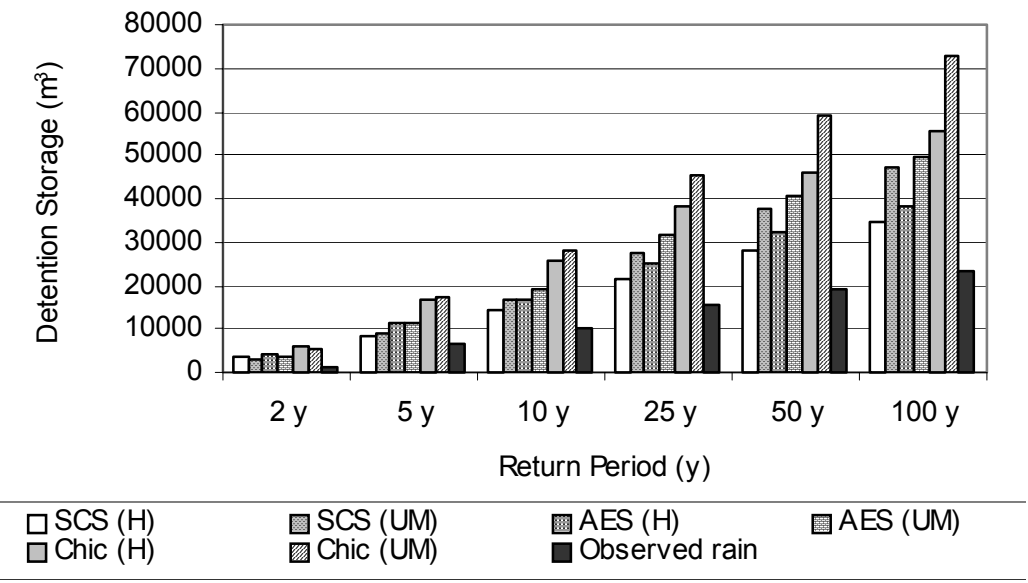

Figure 16.8 Comparing design storages.

\subsection{Conclusions and Recommendations}

Differences in the computed hydrograph peaks and volumes as quantified by design flow and storage capacities is here attributed to variations in the design input hyetographs, and to no other extraneous model factors. Overlooking for the moment the fact that the continuous rain record at hourly time-steps is too coarse for a final conclusion to be drawn, the design capacities determined for the long-term record are now considered to be the 
"best" standard to decide the suitability or otherwise of the designs based on the synthetic distribution patterns. It is then found that almost all the capacities obtained from design storm hyetographs were over-designed. For return periods from $2 \mathrm{y}$ to $10 \mathrm{y}$ the flow capacity and detention storage required to accommodate the design storm hydrographs is greater than those that would be required if the same applications were designed using a historic rain record and continuous simulation.

Sizing for the $25 \mathrm{y}$ return period input design storms are much closer to the design based on the coarse long-term rain record. To compare the $2 \mathrm{y}$ to 10 y return period designs, a safety factor F may be defined:

$$
\mathrm{F}=\frac{\text { Design capacity determined by design storm }}{\text { Minimum required capacity determined from continuous record }}
$$

where $\mathrm{F}$ is typically $\quad 0 \leq \mathrm{F} \leq 10$

and $\quad \mathrm{F}>1$ denotes Over-design

$\mathrm{F}<1 \quad$ denotes Under-design

$\mathrm{F}=1 \quad$ denotes Optimal design

Also the SCS type 2 and the AES Canadian design storms give flows and storage capacities relatively closer to the long-term coarse rain data while the Chicago Design storms produce over-sized flow and storage capacities, perhaps indicating that the latter do not represent typical rainfall distributions for Southern Ontario.

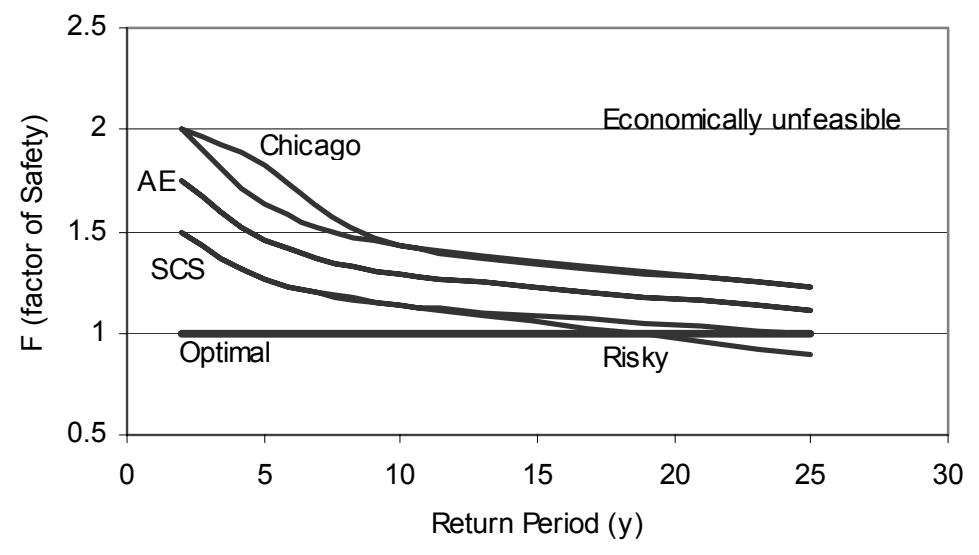

Figure 16.14 Comparison of pipe sizes determined using synthetic design storm distributions and long-term observed rain. 
Figures $16.14,16.15$ and 16.16 show how the design storm designs compare to the design obtained from long-term observed rain data.

The study should be repeated using a long-term rain record of fine time resolution.

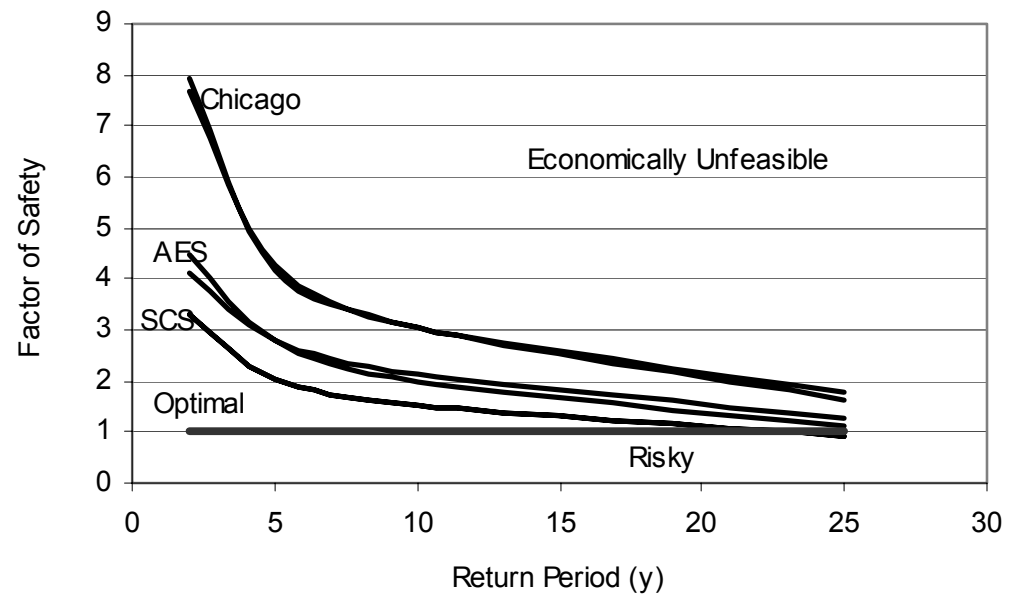

Figure 16.15 Comparison of flow capacities using synthetic design storm distributions and long-term observed rain

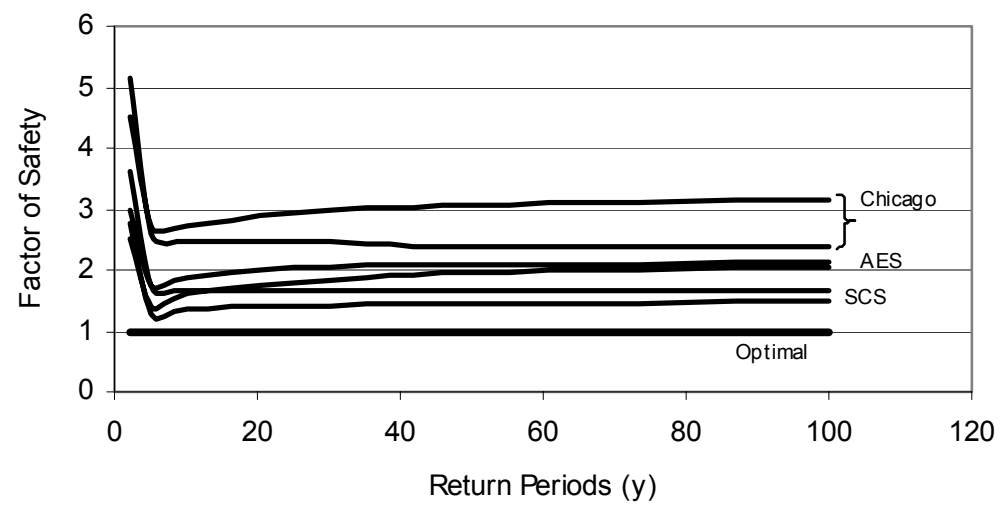

Figure 16.16 Comparison of storage capacities using synthetic design storm distributions and long-term observed rain 
Selection of design storm duration warrants attention and depends on the objectives of the storm synthesis. Short duration storms are appropriate for conveyance structures that are sized for peak runoff while long duration storms are a better choice for designing stormwater detention facilities as they generate greater runoff volumes. Use of long-term observed rain data would, however, be the most accurate. It is therefore recommended that long-term observed rain records be used in hydrologic practice.

\section{References}

Hall, M. J. 1984. Urban Hydrology

Hogg, W.D. 1982 Distribution of Rainfall with Time: Design Considerations. Paper presented at the American Geophysical Union Chapman conference on Rainfall Rates, April 27-29, Urbana, IL

James et al. 2003. User's Guide to SWMM. CHI. Guelph, Ontario, Canada. ISBN: 09736716-1-0 942 pp.

Watt W.E. Lathem, K.W. Neill, C.R., Richards, T.L. 1989. Hydrology of Floods in Canada: A Guide to Planning and Design. Kingston University Ontario Canada Reactor Thermal-Hydraulics (NURETH-11), Avignon, France, October 2-6. 